\title{
IMAGEM PICTÓRICA E REPRESENTAÇÃO
}

Álvaro Cardoso GOMES ${ }^{1}$

Eliane de Alcântara TEIXEIRA²

\begin{abstract}
${ }^{1}$ Professor Titular da USP, Coordenador do Mestrado Interdisciplinar da UNISA (São Paulo), autor de A Literatura e as Artes Visuais: diálogo em espelho (em col. com Eliane de Alcântara Teixeira), Alçapão de Imagens, O poeta que fingia, Memórias Quase Póstumas de Machado de Assis. E-mail: acgomes@unisa.br; alcgomes@uol.com.br

${ }^{2}$ Professora Doutora pela USP, Professora da UNIBr (São Sebastião) e do Middlebury College (VT, EUA), autora de $A$ Literatura e as Artes Visuais: diálogo em espelho (em col. com Álvaro Cardoso Gomes), O Insólito e a Desumanização em Ensaio sobre a Cegueira de Saramago. E-mail: eatgan@gmail.com
\end{abstract}

Recebido em: 11/11/2015 - Aprovado em: 13/07/2016 - Disponibilizado em: 18/12/2016

\section{RESUMO:}

Tendo como centro de estudo a tela do pintor holandês Jan Van Eyck, O Casal Arnolfini, o artigo tenta analisar a questão da representação em pintura. Na tela, o real, entendido como um sistema organizado, obediente a leis mecânicas, de acordo com os princípios racionalistas do Renascimento, tem seu reflexo numa arte que é a representação fiel dessa ordem.

Palavras-chave: Pintura. Representação. Burguesia. Renascimento.

\section{ABSTRACT:}

This article analyzes the issue of representation in painting, having as goal the canvas of the Dutch painter Jan Van Eyck, The Arnolfini Couple. On the canvas the real world, understood as an organized system, obedient to mechanical laws, according to the rationalist principles of the Renaissance, has its representation in one kind of art that is a faithful representation of its order.

Keywords: painting. Representation. Bourgeoisie. Renaissance.

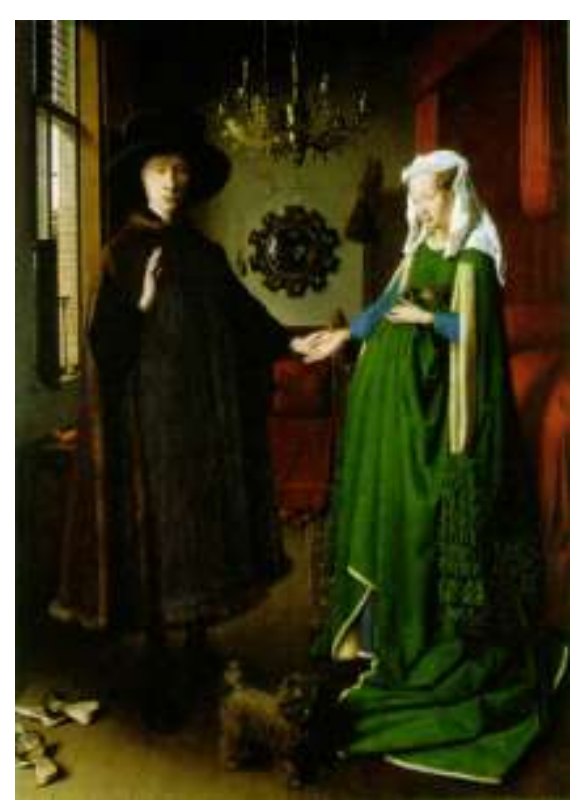

Fig. 1- O Casal Arnolfini, tela de Jan Van Eyck
A tela de Jan Van Eyck (1390 1441), O Casal Arnolfini (1434), a uma primeira mirada, chama a atenção do espectador pela minuciosa reconstrução do real. Tudo parece perfeito, como a mais acabada das fotografias, quando se observa não só a beleza das cores e formas, sua perfeita adequação ao motivo central, mas também a textura dos tecidos, das peles, o rigor na construção dos objetos, na reprodução da figuras, na sugestão de volume e profundidade. A paixão miniaturista da arte flamenga leva o pintor a dar ao segundo plano tanto destaque quanto ao primeiro. 
Cada detalhe - as joias, as frutas, peças da indumentária - é trabalhado minuciosamente, como se tivesse vida própria, autônoma, em relação ao todo. É preciso notar, porém, que a excessiva realidade do quadro, pela artística arrumação dos dados que o compõem, acaba por sugerir uma atmosfera mágica ou um quase surrealismo, quando se instaura diante de nós essa absurda ordenação do real.

No quadro, os móveis, os objetos, as roupas das personagens indiciam riqueza e a classe social a que pertencem os figurantes que são burgueses. O poderio dessa classe laboriosa, ainda mais no Flandres, fica evidente no fato de ela marcar sua ascensão pela representação pictórica, o que, na época, era uma forma de prestígio. Expor aos olhos do espectador a sua intimidade, a sua riqueza, tinha uma meta, que era de as personagens projetarem-se como um par de figuras gradas numa sociedade que prezava a hierarquia manifesta pela posse, pelo dinheiro. Como costumava acontecer nas telas do período, mormente as produzidas no Flandres, aparecem no quadro muitos detalhes que, no caso, parecem ter sido colocados ali sem justificativa aparente. Todavia, a um olhar mais atento, percebe-se que os objetos servem para atestar a riqueza do casal. Assim, os móveis, as roupagens e mesmo as frutas colocadas no parapeito da janela, foram ali dispostos, de acordo com um cálculo, que tanto pode ter sido do pintor quanto do mercador ou mesmo de ambos. Nessa estudada arrumação, oferecem-se aí objetos de muitos países, como a Rússia, Turquia, Itália, Inglaterra, França.

Aproveitando-se de sua condição de mercador, Arnolfini deve ter trazido desses lugares tudo o que o dinheiro poderia comprar e que propiciasse a ele e à esposa o maior conforto. Quanto aos móveis, chamamos a atenção para o amplo leito de dossel, provido de ricos cortinados, o tapete, talvez procedente da Turquia, de modo muito provável, um objeto muito caro na época, assim como o requintado espelho, que exibe em seu entorno 10 das 14 estações da Via Sacra. Mas há ainda o lustre dourado e, sobretudo as laranjas, importadas do sul da Europa, que eram uma raridade no norte do continente. E há que lembrar, como não poderia deixar de ser, as roupas das personagens. O homem veste o tabardo, um manto com mangas e capuz, com caríssimos remates de pele de marta, enquanto a mulher usa um belo vestido, de cores vivas e alegres, com punhos de arminho, um colar, anéis e um cinto todo de ouro. A exibição de tantos bens de alto valor serve como ostentação - um modo de o casal exibir a ascensão numa sociedade altamente estratificada, apesar de serem burgueses e mercadores. A esse respeito, Hauser observa que "entre as características do burguês estão a de se perseguir metas positivas e utilitárias (...), a de entender por respeitabilidade solidez comercial e bom nome" (HAUSER, 1969: p. 369-370). Daí a necessidade de ostentação. 
Van Eyck compõe a cena com figuras de corpo inteiro, que representam muito mais a função do homem do que a sua personalidade (FRANCASTEL, 1973: p. 49), ao contrário do que acontece quando se procura pintar um tronco ou mesmo um rosto. Contudo, apesar de constatarmos que o artista teve, acima de tudo, a intenção de fazer que representassem a classe social a que pertencem, é importante assinalar que ainda é possível apontar nas figuras indícios de sua individualidade. Contrariamente à pintura medieval, em que as figuras se diferenciam hierarquicamente apenas pela posição social e/ou religiosa, a pintura renascentista dá valor ao que há de individualizado no ser humano, exatamente pelo fato de que ela registra um momento histórico e cultural em que o homem passa a ser valorizado como indivíduo ou ainda o momento em que nasce o homem moderno, um ser diferenciado em relação à massa anônima. Nesse sentido, mesmo privilegiando o corpo inteiro das personagens, o pintor chama a atenção para aspectos personalizados das figuras, a começar pelo nome do casal.

Se o interesse pela individualidade não começa propriamente no Renascimento e já se verifica em parte durante a Idade Média, no entanto, a forte consciência do individualismo só vai se manifestar durante os séculos XV e XVI, como salienta Hauser: “o individualismo do Renascimento foi novo somente como programa consciente" (HAUSER, 1969: p. 346), ou mesmo
Buckhardt, para quem, durante a Idade Média, "as duas faces da consciência, a face objetiva e a face subjetiva, estavam de alguma maneira veladas", pois o homem “apenas se conhecia como raça, povo, partido, corporação, família ou sob uma outra forma geral e coletiva". Esse véu, ainda segundo o teórico alemão, é rasgado, pela primeira vez, na Itália quando então se desenvolve "o aspecto subjetivo; o homem torna-se indivíduo espiritual e tem consciência deste novo estado" (BUCKHARDT, 1973: p. 107).

Voltando à contemplação do quadro de Van Eyck, observamos que o casal está de mãos dadas: o homem, mais perto do exterior, tem atitude firme e seu rosto, com os olhos vagos, é impassível. As cores da indumentária (roxo e negro) acentuam-lhe a sobriedade da postura. Seus gestos são pausados. O pé direito avança; a mão direita abre o espaço à frente. A mão esquerda como que apresenta a companheira. Esta, vestida de cores delicadas e suaves (porém muito mais vivas que as vestes do marido), simplesmente ataviadas de peles e dourados, tem um olhar doce e dir-se-ia esboçar leve sorriso de Gioconda, todavia desprovido de mistério. A cabeça inclinada indica a posição que ocupa na família: submissa, introduz-se secundariamente em cena, atrás do marido. Grávida, protege o ventre com a mão esquerda; a mão direita deixa-se levar por aquele que é o chefe da família. 
Por meio do cenário, o pintor salienta as posses do casal. Há um leito vermelho, a pequena cômoda, as frutas tropicais (um sinal de riqueza na época, já que frutas desse tipo eram bastante raras na Europa), a janela e um retalho de natureza. Entre os dois, há um cão (símbolo de fidelidade), uma cadeira, um espelho (que reflete as figuras e objetos por detrás, fornecendo a outra dimensão do quarto). No forro, dependura-se um lustre com uma vela curiosamente acesa, já que a cena se passa durante o dia e o quarto é profusamente iluminado pela janela aberta. As cores são basicamente o verde, o azul, o branco, o vermelho, o negro, o laranja, o castanho. Para a mulher, convergem as cores claras: verde, azul e branco. O verde, cor complementar, é realçado pela primária vermelho, ao fundo. A janela, deixando entrar a luz, acentua o rubro, estabelecendo, conseqüentemente, o equilíbrio dos tons. $\mathrm{O}$ homem usa cores sóbrias: roxo e negro, contrastadas pelo amarelo-laranja dos frutos e do castanho-claro da moldura da janela e do soalho. A luz, por sua vez, é que estabelece as nuanças e, obviamente, ajuda a compor a diversas camadas e dimensões do quadro, sugerindo profundidade, primeiro e segundo planos, etc. Engenhosamente, Van Eyck utiliza-se do recurso da vela para realçar o dourado do lustre e sugerir a evidente intencionalidade artística na estudada arrumação da luminosidade.

O espelho está colocado bem ao centro da tela. Sua conformação lembra a do olho de peixe, lente deformadora que, alargando o ângulo de visão, dá outras dimensões e perspectivas da tela: as costas das figuras e a parte de frente do quadro, onde, evidentemente, se situa o receptor:

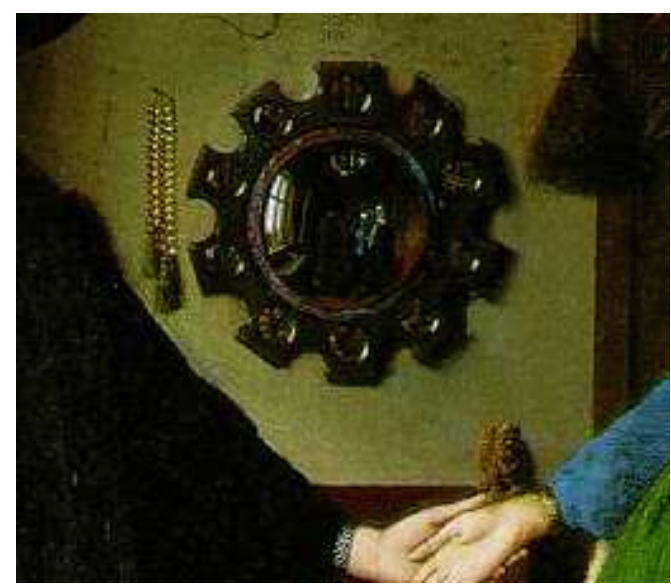

Fig. 2 - Fragmento de O Casal Arnolfini, de Jan Van Eyck

O espelho constitui um truque pictórico, por meio do qual, o pintor tem a possibilidade de fornecer a imagem total dos objetos retratados, isto é, as duas dimensões da cena, sem ferir o principio da verossimilhança. $\mathrm{O}$ real organiza-se em duas faces, e o pintor resolve tecnicamente $\mathrm{o}$ problema do buraco à frente da tela, construindo um todo que se fecha em si mesmo. As figuras, os objetos revelam suas partes ocultas. O que interessa é o real, aí, diante de nós, o mundo palpável, visível que nada esconde e aparentemente tudo revela.

$O$ quadro de Van Eyck seria comumente classificado de figurativo. Que a pintura figurativa, por sua vez, seja icônica, não há dúvida. Contudo, os dois termos, figurativa e icônica, têm que ser examinados com atenção, para se evitar a falácia de que a 
pintura não passa de cópia grosseira da realidade. A rigor, o signo icônico tem propriedades em comum, não com o objeto propriamente dito, "mas com o modelo, perceptivo do objeto", segundo Umberto Eco (1974: p. 111-112). Nesse sentido, a palavra "cópia" deve ser bastante atenuada, porque, mesmo na reprodução mais minuciosa de um objeto, sempre há atitude deformadora do sujeito, já que tudo parte de sua percepção das coisas.

A esse propósito, não é custoso lembrar da tela-boutade de Magritte, em que, sob a reprodução de um cachimbo, aparece a seguinte inscrição "isto não é um cachimbo"...

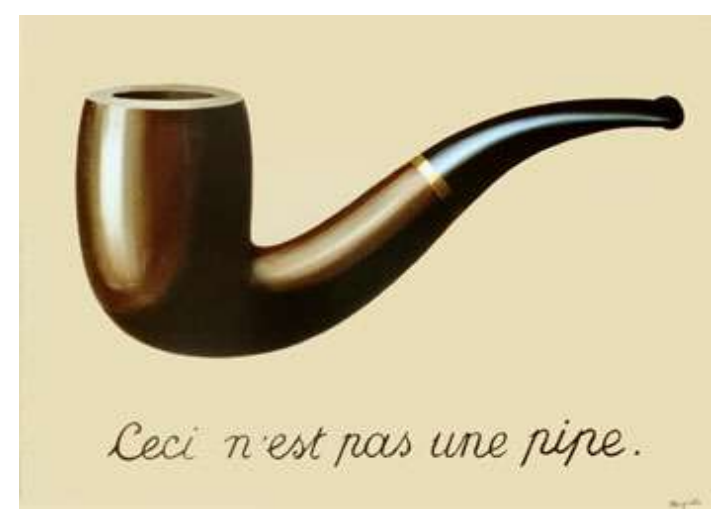

Fig. 3, Ceci n'est pas une pipe, tela de René Magritte

A pintura não se interessa pelos objetos em si; pelo contrário, o pintor visa a estabelecer relações entre cores e formas.

É, pois, importante, na chamada pintura figurativa, a ordenação das coisas do universo sobre a tela e, sobretudo, a relação que elas mantêm entre si. Aparentemente, os objetos são copiados na íntegra na tela de Van Eyck, com fidelidade fotográfica, mas o perfeito equilíbrio entre pessoas e coisas, pelo harmonioso dos tons e pela sábia relação entre cores primárias, secundárias e complementares, dá azo à criação de um novo mundo, regido por leis próprias. Os seres como que adquirem aura na tela, quando então tudo se torna significativo: as vestes, os gestos, o espaço que ocupam, as cores, os tons, etc. A relação de que fala Bracque e que Van Eyck estabelece manifesta-se por meio da sensação de harmonia que a tela provoca. Os objetos estão ali para representá-la. Contudo, onde mais se nota este teor de representação está na idéia da arte como espelho.

Convocamos aqui Abrahms que, em O espelho e a lâmpada, observa o seguinte a respeito do espelho:

O recorrer ao espelho para esclarecer
a natureza de uma ou outra arte
continuou sendo o favorito dos
teóricos da estética, por muito tempo
depois de Platão. Na especulação do
Renascimento a referência ao
espelho é frequiente e explícita
(ABRAHMS, 1962: p. 54).

Essa concepção vem de Platão que inclusive chegou a criticar a arte, julgando-a imperfeita, como se ela fosse apenas uma cópia degradada da aparência do real. Em suma, o poeta e o pintor, segundo o filósofo, apenas fariam cópia em segundo nível, distanciando-se cada vez mais das idéias absolutas. É necessário considerar também que, nesse caso, tornando-se se fiel às coisas, o "eu" acaba por anular-se, aceitando o jugo 
do real objetivo. No entanto, a imitação pura e simples não existe em arte, pelo fato de o artista proceder uma seleção de aspectos do real, levando em conta uma posterior combinação. Em síntese, o que o pintor flamengo faz é organizar o mundo real, de acordo com uma perspectiva, obedecendo às suas concepções de vida e aos padrões culturais da época. Já a ideia de significação dos gestos, da cores, da postura das figuras, anula qualquer julgamento de grosseira mimese.

S. C. Pepper, citado por Abrahms, observa que: "cada uma das maiores visões do mundo é uma espécie de prodigiosa sinédoque, que mostra o universo todo como semelhante a uma de suas partes" (PEPPER, apud ABRAHAMS, 1962: p. 68). A tela de Van Eyck é, pois, uma parte que representa um todo, isto é, os elementos ali contidos, em sua perfeita harmonia, são o reflexo do universo. É possível entender o quadro pequeno (o do espelho, o redondo) como cópia do grande (o retangular), o qual corresponde à harmonia universal. Para Francastel, "existe uma lei, um mistério da natureza, segundo a qual as proporções do corpo humano refletem a ordem universal" (FRANCASTEL, 1973: p. 69). Como se verá adiante, o mundo, entendido como um todo organizado, obediente a leis mecânicas, de acordo com os princípios racionalistas do Renascimento, tem seu reflexo numa arte que é a representação fiel dessa ordem.
Nesse aspecto, $O$ Casal Arnolfini, apesar da individualidade das figuras, é mais do que simples retrato de burgueses endinheirados. Num nível mais complexo, as personagens representam as figuras 0 arquétipo do homem e da mulher (de acordo com as concepções do século XV). Em outras palavras, acontece aqui a retomada de um motivo medieval, adaptado aos valores do Renascimento, ou seja, o da "Sagrada Família". Com efeito, há evidente relação entre as figuras de José e Maria e as do casal Arnolfini, principalmente no ar sereno dos rostos, nos gestos pausados, na gravidez e no olhar inocente da mulher. Há novidades, porém: desaparece ao achatamento que juntava figuras e fundo da pintura medieval; o desenho obedece a uma técnica muito mais apurada; as partes organizam-se por subordinação e não mais por coordenação. $\mathrm{O}$ senso de perspectiva rígida supõe uma visão matematizada do Universo, em oposição ao primitivismo das telas dos artistas medievais. Estrutura e simbologia ordenam-se numa adequação que visa, sobremaneira, à harmonia: a perfeição do desenho, o casal modelar, que encerra em si o germe da criação (a gravidez), em evidente referência à idéia de fecundidade do Classicismo. Esteticamente, a gravidez da mulher corresponde à gravidez do próprio quadro, isto é, o espelho, a reprodução em duplo da cena, semelha o ventre materno e remete ao plano da criação artística. A mãe e o pintor igualam-se, quando ambos (re)produzem o 
real e, nesse sentido, imitam a harmonia do Universo, por meio de uma harmonia particular.

Contudo, dos objetos da tela, é o pequeno espelho que chama a atenção do espectador. É como se o pintor colocasse a sua intenção mimética às claras, utilizando-se do recurso do espelho redondo. Como já dissemos, o espelho serve para introduzir o espaço oculto à visão. Cremos, porém, que sua presença no quadro ultrapassa a simples função reprodutora, exigindo uma reflexão sobre o problema da ilusão na arte. Van Eyck, a rigor, coloca o espectador diante de duas molduras: a retangular e a redonda; a primeira encerra figuras e objetos extremamente fiéis ao real; a segunda, deforma-os. Portanto, a tela provoca dupla ilusão: em primeiro lugar, leva o espectador, pela imitação harmoniosa da realidade, a crer que as pessoas e objetos representados sejam reais (apesar da moldura, que já determina um visão "artística" das coisas) e, em segundo lugar, que os elementos do primeiro plano são o verdadeiro real e que o espelho redondo é sua reprodução artística (daí a deformação, daí os aspectos ocultos, etc.). A sua conformação redonda implica similaridade com o olho humano. Nesse último aspecto, o espelho parece indicar a perspectiva única, dentro da qual se situou o artista que, por sua vez, conduziu o próprio espectador. Convém observar, contudo, que esta obediência do observador ao artista, em outro nível, corresponde àquela do pintor a determinado sistema. O mundo fechado, cuja abertura para o lado do espectador se frustra, pelo uso do espelho, a maravilhosa harmonia das cores, a disposição rigorosa das figuras, representam a obediência do pintor a uma ordem específica. Como reflexo da concepção copernicana e geocêntrica do Universo, o seu enfoque do mundo é único. Desse modo, condicionado pela visão das coisas, segundo determinada perspectiva, Van Eyck também condiciona a visão do espectador, expondo, às claras, um ponto fixo, para onde convergirá o seu olhar.

Mas é possível se pensar nesse espelho também da perspectiva da teoria da recepção. Esse espectador duplica-se - segundo muitos estudiosos da tela, seriam um sacerdote e o próprio pintor. Quanto a este último, não bastasse figurar na tela, numa projeção especular, ainda por cima, deixa uma inscrição no quadro, um pouco acima do espelho: "Johannes van Eyck fuit hic 1434" (“Jan van Eyck esteve aqui em 1434"). Contudo, é possível ir um pouco mais longe, se nos desligarmos da ilusão e pensarmos que, no lugar do espectador/pintor refletido no espelho, poderia se postar outro tipo de espectador, aquele que contemplou e vem contemplando o quadro há séculos. Pois então, é também para ele que Giovanni Arnolfini lança o olhar, de maneira a apresentar seu próprio mundo, formado, principalmente, pela bela esposa (talvez grávida) e, secundariamente, por suas posses: um aposento recheado com tudo o que um 
rico burguês, trabalhando como mercador, poderia ostentar no seu tempo.

A esse propósito, talvez valesse a pena trazer à discussão um comentário poético feito por Murilo Mendes, em que ele trata da participação do espectador privilegiado na tela. Eis o poema:

\section{O Quadro}

É verdade que Giovanni Arnolfini Não olha a mulher - grávida talvez -

Olha antes o espectador

Também

ele protagonista/testemunha (MENDES, 1993, p.81).

O poeta é muito sucinto, no sentido de que se resume a desenvolver apenas a questão do olhar na tela de Van Eyck, a partir da figura de Giovanni Arnolfini, que, de mãos dadas com a esposa, não a contempla e, sim, o espectador da tela. O poema está a serviço da discussão de uma questão metalinguística, ou seja, o poeta quer tratar da teoria da recepção, suscitada por um detalhe significativo da tela: o espelho convexo postado às costas das figuras e que projeta, em miniatura, o que se esconde à frente delas, no caso, na interpretação do sujeito, o espectador/testemunha.

O espectador, chamado pelo olhar de Giovanni Arnolfini, é convidado a entrar nesse mundo, para, em primeiro lugar, também servir de testemunha legal do casamento que ora se realiza, em segundo lugar, da riqueza deles e, em terceiro lugar, da ascensão de uma classe, a burguesa, que passa a ter os mesmo privilégios de uma classe superior - que começa a substituir - a nobreza. Com efeito, a tela, entre outras coisas, é fundamental como o registro histórico de uma profunda mudança social, principalmente nos países do Flandres e na Itália, em que o poder do dinheiro, de certo modo, começa a suplantar o do sangue. Isso, a ponto de um simples mercador merecer posição de destaque, ao ser representado num quadro, não pelo fato de pertencer à nobreza, mas por suas posses. A verticalidade social começa a ser substituída pela horizontalidade, com a valorização dos bens terrenos, o materialismo, ou, se se quiser, o antropocentrismo. E para celebrar esse novo e luminoso mundo que nasce, com todo seu esplendor e beleza, em tudo oposto ao mundo da transcendência, representada, por exemplo, nos quadros medievais de Giotto e Fra Angelico, ainda Van Eyck nos oferta a gravidez da mulher, como símbolo fértil da vinda de um renascimento.

$\mathrm{O}$ poema não tem como interesse a descrição minuciosa de um quadro já de si minucioso, mas, sim, se concentrar em discutir a questão da ilusão, da representação ou, se se quiser, da teoria da recepção. A tela, afinal, foi concebida para os olhos de espectadores, desde o seu tempo até nossos dias. Ver implica deslindar implícitos que o pintor deixou sugerido na tela, por meio de gestos e atitudes das personagens, não 
desenvolvidas no seu todo. Do ponto de vista de Maria João Reynaud (2001, p.42),

[...] a correspondência da poesia com a obra pictórica ou escultórica é encontrada, não raro, num movimento gradual de aproximação, até ao ponto em que a perspectiva se anula e dá lugar a uma reversibilidade do olhar que é da ordem do enigma (REYNAUD, 2001: p. 42).

O enigma está num olhar que se dirige a outro e não identificado olhar: afinal, o comerciante Arnolfini não quer apenas ser visto, junto com sua bela mulher e seus caros objetos de decoração, mas quer mostrar quem é e o que possui, como se constituísse um símbolo vivo de não só uma pessoa, mas também de uma classe em plena ascensão social.

Conclui-se disso que o espectador, chamado pelo olhar de Giovanni Arnolfini, é convidado a entrar nesse mundo, para, em primeiro lugar, também servir de testemunha legal do casamento que ora se realiza, em segundo lugar, da riqueza deles e, em terceiro lugar, da ascensão de uma classe, a burguesa, que passa a ter os mesmo privilégios de uma classe superior, a que começa a substituir, a nobreza. Com efeito, a tela, entre outras coisas, é fundamental como o registro histórico de uma profunda mudança social, principalmente nos países do Flandres e na Itália, em que o poder do dinheiro, de certo modo, começa a suplantar o do sangue. Isso, a ponto de um simples mercador merecer posição de destaque, ao ser representado num quadro, não pelo fato de pertencer à nobreza, mas por suas posses. A verticalidade social começa, pois, a ser substuída pela horizontalidade, com a valorização dos bens terrenos, o materialismo, ou, se se quiser, o antropocentrismo. E para celebrar esse novo e luminoso mundo que nasce, com todo seu esplendor e beleza, em tudo oposto ao mundo da transcendência, representada, por exemplo, nos quadros medievais de Giotto e Fra Angelico, ainda Van Eyck nos oferta a gravidez da mulher, como símbolo fértil da vinda de um renascimento.

\section{Referências Bibliográficas}

ABRAMS, M. A. El espejo y la lámpara, Buenos Aires: Editorial Nova, 1962.

FRANCASTEL, Pierre. A realidade figurativa. São Paulo: Perspectiva, 1973. HAUSER, Arnold. Historia social de la literatura y el arte. III vols., Madrid: Guadarrama, 1969.

ECO, Humberto. A estrutura ausente, São Paulo: Perspectiva, 1974.

BURCKHARDT, Jacob. O Renascimento italiano, Lisboa: Editorial Presença, 1973.

MENDES, Murilo. "O Casal Arnolfini”, Ilustrações, Rio de Janeiro, n. 129/130, jul. 1993, p. 81.

REYNAUD. Maria João. Fernando Echevarría, Enigma e Tranparência. Porto: Caixotim, 2001. 